\title{
Prediction of salmon (Salmo salar) quality during refrigeration storage based on dielectric properties
}

\author{
Jialing $\mathrm{He}^{1,2}$, Feng $\mathrm{Li}^{1,2}$, Yang Jiao ${ }^{1,2^{*}}$ \\ (1. College of Food Science and Technology, Shanghai Ocean University, Shanghai 201306, China; \\ 2. Food Thermal Processing Engineering Technology Research Center, Shanghai Ocean University, Shanghai 201306, China)
}

\begin{abstract}
Dielectric properties are validated to be correlated with the changes of food quality during $4{ }^{\circ} \mathrm{C}$ storage, thus it could be used as predictive indicators for the quality parameters of salmon (Salmo salar) during cold storage. An open-ended coaxial detection method was used to determine the dielectric properties (dielectric constant $\varepsilon^{\prime}$ and dielectric loss $\left.\varepsilon^{\prime \prime}\right)$ of salmon at the frequency range of $20-2500 \mathrm{MHz}$, and to explore the relationship between dielectric properties and volatile base nitrogen (TVB-N), thiobarbituric acid reactants (TBARS), total viable counts (TVC), $\mathrm{pH}$ and $\mathrm{K}$-value in salmon fillets during storage for $7 \mathrm{~d}$. Results showed that the TVB-N, TBARS, TVC and K-value of salmon increased linearly with the increase of storage time, and the $\mathrm{pH}$ decreased firstly and increased subsequently. Also, the dielectric properties $\left(\varepsilon^{\prime}\right.$ and $\left.\varepsilon^{\prime \prime}\right)$ decreased with the increase of frequency, and increased with the increase of storage time. During $7 \mathrm{~d}$ storage, $\varepsilon^{\prime \prime}$ increased the most at the frequency of 27.12 and $40.68 \mathrm{MHz}$, while at the frequency of $915 \mathrm{MHz}$ and $2450 \mathrm{MHz}$, the increase of $\varepsilon^{\prime \prime}$ was smaller. Results analyzed by Pearson correlation analysis showed that significant correlation $(p<0.01)$ was found between $\varepsilon^{\prime \prime}$ and TVB-N and TBARS at the frequency of 27.12, 40.68, 100.00, 300 and $915 \mathrm{MHz}$. The results of the partial least square (PLS) model showed that all the determination coefficients $\left(R_{\text {pred }}^{2}\right)$ were over 0.900 . Especially for TBARS, the $R_{\text {pred }}^{2}$ of PLS- $\varepsilon^{\prime}$ and PLS- $\varepsilon "$ were 0.913 and 0.920 , respectively, and the root mean square error of prediction (RMSEP) were 0.041 and 0.039 , respectively. However, the highest $R_{\text {pred }}^{2}$ for PLS- $\varepsilon^{\prime}$ and PLS- $\varepsilon^{\prime \prime}$ both occurred in TVB-N. Also, the predicted values against measured values of TVB-N, TBARS and TVC of salmon presented a good linear relationship. The linear coefficient $R^{2}$ of TVB-N, TBARS and TVC for PLS- $\varepsilon^{\prime}$ were $0.937,0.910$ and 0.917 respectively, and $0.942,0.917$ and 0.933 respectively for PLS- $\varepsilon "$. The results demonstrated the dielectric properties combined with PLS analysis can be used as a rapid and non-destructive method to predict quality parameters of salmon during $4^{\circ} \mathrm{C}$ storage and could be further applied to other aquatic products.
\end{abstract}

Keywords: seafood, physiochemical quality, dielectric properties, PLS regression, non-destructive food analysis, Salmon DOI: $10.25165 /$ j.ijabe.20211404.6281

Citation: He J L, Li F, Jiao Y. Prediction of salmon (Salmo salar) quality during refrigeration storage based on dielectric properties. Int J Agric \& Biol Eng, 2021; 14(4): 262-269.

\section{Introduction}

Salmon is rich in nutrition and contains protein (lysine, methionine, etc.), fat-soluble vitamins (vitamins $\mathrm{A}$ and $\mathrm{D}$, etc.), trace elements (iron, zinc, calcium, iodine, etc.) and polyunsaturated fatty acids, especially docosahexaenoic acid (DHA) and eicosapentaenoic acid (EPA) ${ }^{[1]}$. Seafood, including salmon, are prone to deteriorate so that monitoring and predicting quality changes during storage are considered critical. The quality of aquatic products is generally evaluated by the amount of total volatile base nitrogen (TVB-N), thiobarbituric acid reactants (TBARS), total viable counts (TVC), $\mathrm{pH}$ and ATP-related compounds. The TVB-N is used to determine the decomposition of protein and fat expressed as nitrogen-containing substances existed in food. The degree of oxidation of food fat can be determined by TBARS, the TVC can be used to evaluate the degree of food spoilage due to bacteria multiplication, and the $\mathrm{pH}$ and

Received date: 2020-11-21 Accepted date: 2020-12-22

Biographies: Jialing He, Master candidate, research interest: aquatic product storage and processing; Email: 13974501128@163.com; Feng Li, MS, Engineer, research interest: food engineering; Email: fli@shou.edu.cn.

*Corresponding author: Yang Jiao, PhD, Associate Professor, research interest: novel food processing and preservation technologies. 999 Hucheng Ring Rd., Pudong New District, Shanghai 201306, China. Tel: +86-21-61908758, Email: yjiao@shou.edu.cn.
ATP-related compounds also are two indicators used to present the freshness of aquatic products ${ }^{[2]}$. Many studies had reported quality changes of aquatic products with useful explanations during different storage conditions. Liu et al. ${ }^{[3]}$ reported that the $\mathrm{pH}$ of grass carp fillets stored at $0^{\circ} \mathrm{C}$ decreased slightly within the initial $3 \mathrm{~d}$ and then increased significantly during the following storage period. The decreases in $\mathrm{pH}$ might be associated with the generation of lactic acid by anaerobic glycolysis and the liberation of inorganic phosphate by degradation of ATP, while the increases might be attributed to the accumulation of ammonia and trimethylamine resulting from autolytic and microbial reactions. And there were no marked changes in initial values of TVB-N of grass carp fillets stored at $0^{\circ} \mathrm{C}$, but a rapid increase was observed during the later stages of storage, accounting for the increases in $\mathrm{pH}$ and protein degradation. Quality changes of Snakehead (Channa argus) fillets stored at $4^{\circ} \mathrm{C}$ were studied. It was found that the total variable counts of snakehead fillets increased rapidly and reached $7.2 \log \mathrm{CFU} / \mathrm{g}$ on day 7, and the initial IMP concentration of the control was $0.66 \mu \mathrm{mol} / \mathrm{g}$, and then increased considerably $(p<0.05)$ on the 3 rd day, accumulating spontaneously at the beginning of storage, and decreased sharply to $0.72 \mu \mathrm{mol} / \mathrm{g}$ on day 11. IMP is sequentially catabolized to HxR by acid phosphatase enzymes and further degraded to $\mathrm{Hx}$ by acid phosphatase ${ }^{[4]}$. Furthermore, more other similar relative researches have been reported ${ }^{[4-7]}$. Because of these changes in 
physicochemical quality of seafood during storage, methods and technologies are crucial for quality determination and prediction. However, the sample preparation process of the traditional detection methods is usually tedious and the operation period is relatively long, which cannot meet the needs of the market and consumers for a fast determination.

Dielectric properties reflect the response of the bound charge in the food molecule to the external electric field. Dielectric constant $\left(\varepsilon^{\prime}\right)$ and dielectric loss $\left(\varepsilon^{\prime \prime}\right)$ are the two components of the dielectric properties, which reflect the storage and loss ability of food molecules to electrostatic energy, respectively. The dielectric properties of food are affected by many factors, such as temperature, frequency, etc., and vary with the food composition ${ }^{[8]}$. The correlations between dielectric properties and the food physiochemical properties have been studied extensively, e.g., the maturity of fruits and vegetables ${ }^{[9,10]}$, the freshness of milk ${ }^{[11]}$, the postmortem aging of livestock and poultry meat ${ }^{[12,13]}$ and food quality ${ }^{[14]}$. Thus, the method of using an open-ended coaxial probe connected to a network analyzer for determining the dielectric properties of food materials ${ }^{[15,16]}$ and correlating with food quality to achieve the goal of fast prediction of food quality has been used by some researchers ${ }^{[10,14,17,18]}$.

Partial least squares (PLS) regression is a multivariate statistical data analysis method, which could be used for regression modeling and correlation analysis among multiple groups of variables $^{[19]}$. It is often used to correlate multiple dependent variables with respect to multiple independent variables ${ }^{[18]}$. Rossi et al. ${ }^{[19]}$ developed a multivariate model based on NIR spectroscopy and PLS regression for predicting the moisture, total ashes, caffeine content in yerba mate. The performance of the regression models showed an $R^{2}>0.90$ with an RMSEP $<0.17 \%$. Shrestha et al. ${ }^{[20]}$ established prediction models based on the Vis/NIR spectrum combined PLS regression to predict the moisture ratio, color, shrinkage and rehydration ratio of apple slices. The PLS regression model showed a good prediction for the quality attributes, especially for the moisture ratio ${ }^{[20]}\left(R^{2}=0.940\right.$, $\mathrm{RMSEP}=0.076)$. However, there is little information on the correlations between dielectric properties and seafood quality parameters during storage, especially salmon.

Thus, in this work, the physicochemical properties and dielectric properties of salmon during cold storage were determined, and the correlation between those was analyzed with a Pearson correlation analysis. Also, the prediction model of physiochemical quality parameters of chilled salmon based on the dielectric properties during storage was established with PLS method. The results assist the development of a methodology for fast predicting the quality changes of salmon fillets during storage.

\section{Materials and methods}

\subsection{Materials and treatment}

Fresh salmon fillets, previously deep-frozen and tempered after transportation from Norway, were purchased from DaRunFa supermarket in Nicheng, Pudong New Area, Shanghai, and the quality was tested and found to meet the requirements of GB $2733-2015^{[21]}$. The purchased salmon fillets were transported to the laboratory in a cooler and refrigerated at $4.0^{\circ} \mathrm{C}$. The dielectric properties and the physicochemical properties including TVB-N, TBARS, TVC, $\mathrm{pH}$ and ATP-related compounds of the salmon fillet samples were tested after 1, 3, 5, 6 and $7 \mathrm{~d}$ of storage, respectively.

\subsection{Determination of total volatile basic nitrogen}

The TVB-N value of refrigerated salmon samples was determined using the Kjeldahl method with a FOSS Kjeltec ${ }^{\mathrm{TM}} 8400$ fully automatic Kjeldahl apparatus (Kjeltec 8400, FOSS Kjeltec, Hilleroed, Denmark). Two grams ( $2.0 \mathrm{~g})$ of the minced sample was put into a $750.0 \mathrm{~mL}$ digestive tube, and $5.0 \mathrm{~g}$ light magnesium oxide was added into the tube as a catalyst, and then the tube was placed on the sample holder to distill. Meanwhile, $1.0 \%$ boric acid solution containing a mixed indicator produced from methylene blue was used to absorb the distillate. Afterward, the boric acid solution was titrated with $0.01 \mathrm{~mol} / \mathrm{L}$ hydrochloric acid solution. The TVB-N value was expressed as $\mathrm{mg} / 100 \mathrm{~g}$, and triplicates were conducted for each sample.

\subsection{Determination of thiobarbituric acid reactive substance}

TBARS is a widely used index to evaluate the degree of fat oxidation. The determination method is slightly modified from a previously published research ${ }^{[22]}$. Five grams $(5.0 \mathrm{~g})$ of minced fish were placed in a conical bottle. Then, $25.0 \mathrm{~mL} 7.5 \%$ trichloroacetic acid (containing $0.1 \%$ EDTA) was added, and the bottle was shaken for $30.0 \mathrm{~min}$. Then the solution was filtered with three layers of filter paper, $5.0 \mathrm{~mL}$ filtrate was transferred into a test tube, $5.0 \mathrm{~mL} 0.02 \mathrm{~mol} / \mathrm{L}$ thiobarbituric acid was added and mixed evenly. After being heated in a $90.0^{\circ} \mathrm{C}$ constant temperature water bath for $40.0 \mathrm{~min}$, and cooled in cold water for $30.0 \mathrm{~min}$, the solution was centrifuged at $239 \mathrm{~g}$ for $5.0 \mathrm{~min}$. The supernatant was obtained and $5.0 \mathrm{~mL}$ chloroform was added into the solution to obtain the absorbance values using a UV-Visible Spectrophotometer (Evolution 220, Thermo Scientific, Waltham, USA) at $600 \mathrm{~nm}$ and $532 \mathrm{~nm}$. Triplicates were conducted in each experiment. The results were expressed in $\mathrm{mg} \mathrm{MDA} / \mathrm{kg}$, and the calculation equation was as follows:

$$
\text { TBARs }(\mathrm{mg} \text { MDA } / \mathrm{kg})=\frac{\left(A_{532}-A_{600}\right) \times 72.6 \times 1000}{155 \times 10}
$$

where, $A_{532}$ is the absorbance value at $532 \mathrm{~nm} ; A_{600}$ is the absorbance value at $600 \mathrm{~nm}$.

\subsection{Determination of total viable counts}

The total viable counts were determined according to the national standard GB4789.2-2016 ${ }^{[23]}$. Twenty-five grams $(25.0 \mathrm{~g})$ of salmon fillet was sampled, minced, and put into a sterile homogenization bag and homogenized in $225.0 \mathrm{~mL}$ sterile physiological saline $(0.85 \%)$ solution with a homogenizer (Basic Panoramic, IUL, S.A., Barcelona, Spain). The homogenized samples were diluted serially (1:10). According to pre-experiment, the appropriate dilution multiple was selected to make a series of gradient bacterial suspensions and $1.0 \mathrm{~mL}$ of each gradient diluent was spread onto the sterile petri dish, covered the culture medium and shaken well. After cooling down, the bacterium was incubated at $(30 \pm 1)^{\circ} \mathrm{C}$ for $72 \mathrm{~h}$. Each trial was repeated three times, and all counts were expressed in $\log (\mathrm{CFU} / \mathrm{g})$.

\subsection{Determination of $\mathrm{pH}$}

The changes in $\mathrm{pH}$ could also reflect the freshness of salmon during cold storage. Ten grams $(10.0 \mathrm{~g})$ minced salmon fillet were dispersed in $100.0 \mathrm{~mL}$ distilled water, stirred for $30.0 \mathrm{~min}$ and then filtered. The $\mathrm{pH}$ of the supernatant was measured using a digital pH meter (FE20K, METTLER TOLEDO Instrument Co., LTD, Shanghai, China). Each experiment was repeated three times.

\subsection{Determination of the concentration of ATP-related compounds and $\mathrm{K}$-value}

ATP-related compounds include adenosine triphosphate (ATP), adenosine diphosphate (ADP), adenosine monophosphate (AMP), inosine 5'-monophosphate (IMP), hypoxanthine riboside (HxR), and hypoxanthine (Hx). During postmortem and 
subsequent storage, ATP in fish muscle undergoes the following degradation process: ATP $\rightarrow$ ADP $\rightarrow$ AMP $\rightarrow$ IMP $\rightarrow \mathrm{HxR} \rightarrow$ $\mathrm{Hx}^{[24]}$. The K-value is commonly used to evaluate the freshness of aquatic products during storage and the value correlates with the degradation and accumulation of ATP-related compounds ${ }^{[25]}$. Generally, the K-value of fresh fish was lower than $20 \%$, while moderately fresh fish was between $20 \%-50 \%$, and a K-value higher than $70 \%$ indicated the spoilage of fish ${ }^{[26]}$.

ATP-related compounds extraction was carried out according to the method described by Huang et al. ${ }^{[27]}$ with some modifications. Two grams $(2.0 \mathrm{~g})$ of the fish sample was homogenized (FJ200-SH, Shanghai Specimen and Model Factory, Shanghai, China) for $1.0 \mathrm{~min}$ with $20.0 \mathrm{~mL}$ of $10 \%(\mathrm{w} / \mathrm{v})$ cold perchloric acid (PCA) solution in an ice bath. After centrifuging at $10621 \mathrm{~g}$ for $15.0 \mathrm{~min}$ at $4^{\circ} \mathrm{C}$, the supernatant was collected, while the sediment was mixed with $10.0 \mathrm{~mL}$ of $5 \%$ cold PCA and centrifuged at $10621 \mathrm{~g}$ for $15.0 \mathrm{~min}$ at $4^{\circ} \mathrm{C}$. The supernatant was collected and the above procedure was repeated. The supernatants obtained were combined, and the $\mathrm{pH}$ was adjusted to 5.8-6.0 with $10.0 \mathrm{~mol} / \mathrm{L}$ and $1.0 \mathrm{~mol} / \mathrm{L}$ sodium hydroxide solutions, and the volume was made up to $50.0 \mathrm{~mL}$ with $4^{\circ} \mathrm{C}$ ultrapure water, and stored at below $-20^{\circ} \mathrm{C}$ for later HPLC analysis.

$K$-value was measured by a reverse-phase high-performance liquid chromatograph (HPLC) (Agilent 1260 Infinity, Agilent Technologies Inc., Palo Alto, USA) $)^{[24]}$. The Ultimate ${ }^{\circledR}$ AQ-C18 column $(4.6 \mathrm{~mm} \times 250.0 \mu \mathrm{mm} \times 5.0 \mu \mathrm{m})$ was installed inside a thermostatic compartment for use at a temperature of $35^{\circ} \mathrm{C}$. The mobile phase were $0.02 \mathrm{~mol} / \mathrm{L}$ phosphate buffer $(\mathrm{pH}=6.0)(\mathrm{A})$ and methanol (HPLC $>98 \%$ ) (B), and the flow rate was $1.0 \mathrm{~mL} / \mathrm{min}$ under gradient elution conditions: $0.00 \mathrm{~min}: 100 \% \mathrm{~A}+0 \% \mathrm{~B}$; 8.00 min: $100 \%$ A $+0 \%$ B; $8.01 \mathrm{~min}: 97 \% \mathrm{~A}+3 \% \mathrm{~B} ; 10 \mathrm{~min}: 97 \%$ $\mathrm{A}+3 \% \mathrm{~B} ; 10.01 \mathrm{~min}: 94 \% \mathrm{~A}+6 \% \mathrm{~B} ; 15 \min : 94 \% \mathrm{~A}+6 \% \mathrm{~B}$; $23.01 \mathrm{~min}: 70 \% \mathrm{~A}+30 \% \mathrm{~B} ; 24.0 \mathrm{~min}: 100 \% \mathrm{~A}+0 \% \mathrm{~B} ; 25 \mathrm{~min}:$ $100 \% \mathrm{~A}+0 \% \mathrm{~B}$. The samples were filtered through a $0.22 \mu \mathrm{m}$ membrane and analysis was carried out by injecting $20.0 \mu \mathrm{L}$ of sample and detection was monitored at $254 \mathrm{~nm}$. The K-value was calculated according to the following equation:

$$
\mathrm{K}(\%)=\frac{H x R+H x}{A T P+A D P+A M P+I M P+H x r+H x} \times 100 \%
$$

\subsection{Determination of dielectric properties}

The dielectric properties of refrigerated salmon fillet samples were measured with an open coaxial probe (Agilent N1501A, Agilent Technologies Inc., Palo Alto, USA) connected to a vector network analyzer (Agilent E5071C, Agilent Technologies Inc., Palo Alto, USA). Also, a self-built sample holder $(d=2.5 \mathrm{~cm}, h=$ $10.0 \mathrm{~cm}$ ) was used to hold the sample for dielectric property measurement. Before measurements, the vector network analyzer was turned on for $1 \mathrm{~h}$ for warming up. Then the scanning type of the software was set to linear scanning. The scanning frequency range was set as $20-2500 \mathrm{MHz}$ (1241 data points) in the software. The analyzing systems were calibrated before each independent measurement to avoid experimental errors. The calibration process was divided into three steps, which are air, short circuit and $(25.0 \pm 0.5)^{\circ} \mathrm{C}$ deionized water ${ }^{[28]}$. Salmon fillets were then cut into cylindrical shapes $(d=2.0 \mathrm{~cm}, h=10.0 \mathrm{~cm})$ and fitted into the self-built sample holder. The open-ended measuring probe was installed to contact the sample surface and started measuring. The dielectric properties of refrigerated salmon were measured within a frequency range of 20-2500 MHz. Each experiment was repeated three times. Detailed equipment information could be found in the literature ${ }^{[29]}$.

\subsection{Regression models}

The partial least square (PLS) method was used to establish a regression prediction model in the measured frequency range with the dielectric properties (PLS- $\left.\varepsilon^{\prime}, \mathrm{PLS}-\varepsilon^{\prime \prime}\right)$ at the selected frequency as independent variables and the physiochemical quality (TVB-N, TBARS, TVC) as dependent variables. The prediction accuracy of the models was evaluated in terms of coefficient of determination $\left(R_{\text {pred }}^{2}\right)$ and root mean square error of prediction (RMSEP) in an external prediction set. A $R_{\text {pred }}^{2}$ was used to represent the correlations between the predicted and experimental values $^{[30]}$. A $R_{\text {pred }}^{2}$ value closer to 1 indicated a perfect fitting, and the RMSEP is used to evaluate the prediction ability of the model to external samples. A larger $R_{p r e d}^{2}$ and a smaller RMSEP indicated a higher fitting and prediction accuracy of the model. The $R_{\text {pred }}^{2}$ and RMSEP were calculated as follows ${ }^{[30,31]}$.

$$
\begin{gathered}
R_{\text {pred }}^{2}=1-\frac{\sum_{j=1}^{m}\left(\widehat{y_{J}}-y_{j}\right)^{2}}{\sum_{j=1}^{m}\left(y_{j}-\overline{y_{j}}\right)^{2}} \\
\text { RMSEP }=\sqrt{\frac{1}{m} \sum_{j=1}^{m}\left(\widehat{y_{J}}-y_{j}\right)^{2}}
\end{gathered}
$$

where, $m$ is the sample size of prediction $(j)$ sets; $\widehat{y_{J}}$ is the model-predicted value of the sample; $y_{j}$ is reference (measured) value of the sample; $\overline{y_{j}}$ is reference mean value of the sample.

\subsection{Data processing and analysis}

The results were expressed as means \pm standard deviation and analyzed with SPSS 25.0 software (SPSS Inc., Chicago, USA). A Pearson's correlation analysis was carried out to obtain the correlation between dielectric properties and various quality indexes, and values of $p<0.05\left(^{*}\right)$ were considered as significant correlation, while $p<0.01(* *)$ were considered as very significant correlation. The Origin 9.1 software was used for graphic drawing and PLS prediction model establishment.

\section{Results and discussion}

\subsection{Effect of storage time on the physicochemical quality of salmon}

Figure 1 showed the changing trend of TVB-N, TBARS and TVC of salmon with refrigerated storage time. Results showed that the TVB-N, TBARS and TVC of refrigerated salmon increased linearly within the storage period. It could be seen from the figure that after $7 \mathrm{~d}$ of $4^{\circ} \mathrm{C}$ storage, the TBARS value of salmon increased to $0.80 \mathrm{mg} \mathrm{MDA} / \mathrm{kg}$, TVB-N increased from 7.42 to $17.48 \mathrm{mg} / 100 \mathrm{~g}$, which did not exceed the limit of secondary freshness (TVB-N $<20.00 \mathrm{mg} / 100 \mathrm{~g}$ ). During the storage process, as time extended, nitrogen-containing macromolecules like protein and peptides would covert to volatile compounds chemicals under the action of microbes ${ }^{[3,24]}$. Researchers also studied the quality changes of silver carp and white shrimp during storage. They reported that the values of TVB-N and TBARS of silver carp increased from $(11.4 \pm 2.9) \mathrm{mg} / 100 \mathrm{~g}$ to nearly $50 \mathrm{mg} / 100 \mathrm{~g}$ and $(0.51 \pm 0.11) \mathrm{mg} \mathrm{MDA} / \mathrm{kg}$ to over $1.00 \mathrm{mg} \mathrm{MDA} / \mathrm{kg}$ after $6 \mathrm{~d}$ storage at $4^{\circ} \mathrm{C}$, respectively ${ }^{[32,33]}$. During storage, the value of TVB-N of white shrimp increased to $33.54 \mathrm{mg} / 100 \mathrm{~g}$ on the 8 th day, which exceeded the spoilage limit of shrimp ${ }^{[32,33]}$. The oxidation of lipids is attributed to the microbial growth and the activity of oxidase, and also the protein degradation. However, the TVC value of salmon after $7 \mathrm{~d}$ of cold storage exceeded the limit value of $5.70 \log (\mathrm{CFU} / \mathrm{g})$ on the 6th day, so it could be considered that the shelf life of $4^{\circ} \mathrm{C}$ refrigerated salmon was less than $6 \mathrm{~d}$. This is because the surface of salmon fillet is contaminated by microbes during storage from the environment. 


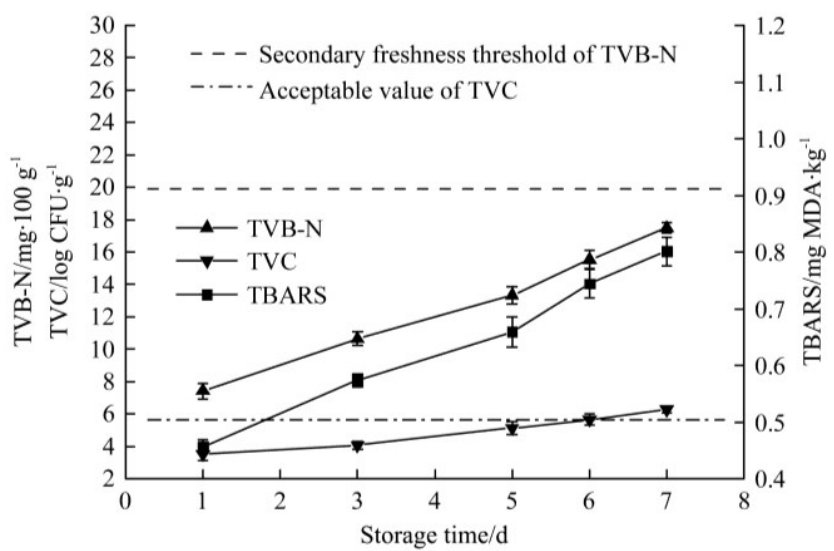

Figure 1 Changes in physiochemical properties of salmon during refrigeration storage

\subsection{Changes of $\mathrm{pH}$ and $\mathrm{K}$-value of salmon}

The $\mathrm{pH}$ of fish flesh was influenced by various biochemical factors during storage, such as glycolysis, the degradation of ATP-related compounds, and the metabolites produced by spoilage

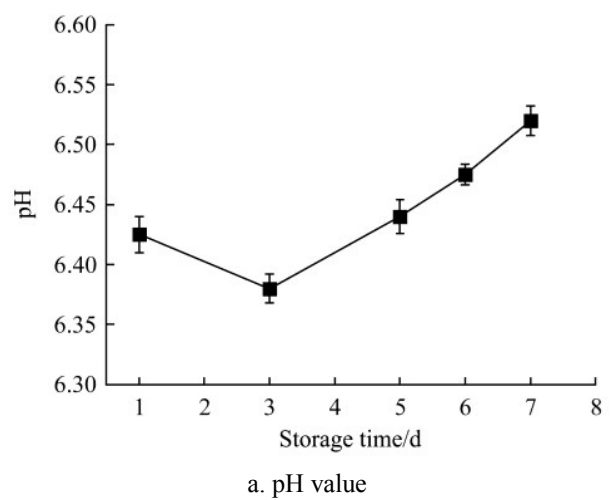

bacteria $^{[34]}$. The $\mathrm{pH}$ values decreased at the first $3 \mathrm{~d}$ and then increased continuously as the storage time increased (Figure 2a). The initial $\mathrm{pH}$ value of salmon fillet was $6.43(1 \mathrm{~d})$, decreased to 6.38 on day 3 , and reached 6.52 on day 7 . The initial decrease in $\mathrm{pH}$ might be due to the lactic acid produced by anaerobic glycolysis of glucose, and the liberation of inorganic phosphate by the degradation of $\mathrm{ATP}^{[35,36]}$. The subsequent increase might be attributed to the accumulation of nitrogen-containing compounds like ammonia and biogenic amines produced by the degradation of protein. Thus, the increase in $\mathrm{pH}$ agreed with the increase of TVB-N value.

Results showed that the $\mathrm{K}$-value of salmon fillets increased continuously with storage time (Figure $2 b$ ), indicating the decline in quality of salmon fillets, which could be expressed as the degradation of ATP and accumulation of HxR and Hx. The initial $\mathrm{K}$-value of salmon fillets was $14.15 \%$ on day 1 , and increased to $50.04 \%$ on day 5 , which indicated the acceptability of fish. After $7 \mathrm{~d}$ of cold storage, its $\mathrm{K}$-value reached $88.89 \%$ which was higher than $70 \%$, indicating the spoilage of salmon fillets. This result is in agreement with many other findings ${ }^{[26,37,38]}$.

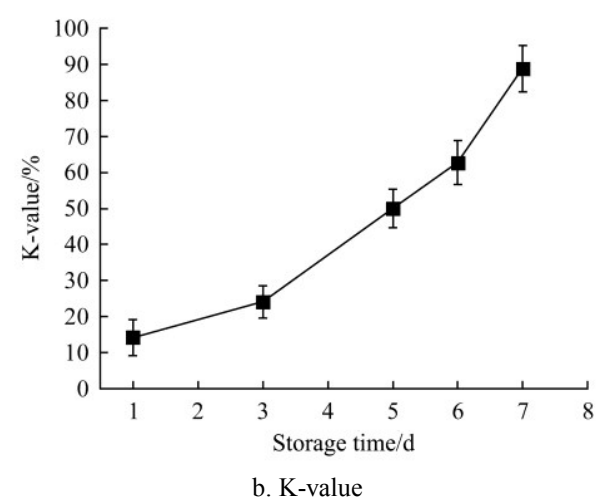

Figure 2 Changes in $\mathrm{pH}$ and $\mathrm{K}$-value of salmon fillets during storage at $4{ }^{\circ} \mathrm{C}$

\subsection{Changes in the concentration of ATP-related compounds}

At the ATP degradation process, IMP was regarded as the major intermediate nucleotides, which was a flavor enhancer. While HxR and Hx attributed to bitterness and off-odor. The accumulation of HxR and $\mathrm{Hx}$ in seafood correlates well with the degradation of fish quality and freshness. The nucleotide's catabolism was caused by the autolysis of muscle, resulted in the transformation of ATP towards IMP, while the endogenous enzyme and microorganisms were the major factors contributing to hydrolyzing $\mathrm{HxR}$ to $\mathrm{Hx}^{[39,40]}$.

As shown in Figure 3, the changes in concentration of ATP, ADP and AMP gradually decreased throughout the whole storage period at $4^{\circ} \mathrm{C}$. The concentration of IMP had no significant change in the first $3 \mathrm{~d}(1 \mathrm{~d}: 1.80 \mu \mathrm{mol} / \mathrm{g}, 3 \mathrm{~d}: 1.79 \mu \mathrm{mol} / \mathrm{g})$, but then decreased sharply during the subsequent storage. This was because IMP degraded to HxR and then converted to Hx due to both autolytic and bacterial enzymes ${ }^{[41]}$. Meanwhile, an increasing and then decreasing change trend was observed in HxR. On the first day, the concentration of HxR was $0.83 \mu \mathrm{mol} / \mathrm{g}$, and reached the maximum $(1.03 \mu \mathrm{mol} / \mathrm{g})$ on day 3 . The increase of HxR is due to the conversion of IMP, while the sharp decrease is the consumption of IMP and accumulation of $\mathrm{Hx}$ with the extension of storage time, resulting in a constant increase in the concentration of $\mathrm{Hx}$ at the later storage.

Some methods and novel technologies were developed to inhibit the enzymatic activities and metabolites of seafood and protect them from deterioration ${ }^{[25,40]}$. The effects of vacuum impregnated fish gelation and grape seed extract on metabolite profiles of tilapia fillets during storage were studied, and the results showed the content of IMP in the control group $(0.55 \mathrm{mg} / 100 \mathrm{~g})$ on day 6 was significantly $(p<0.05)$ lower than that of the coated samples $(1.27-1.69 \mathrm{mg} / 100 \mathrm{~g})$. Also, coating treatments reduced the formation of $\mathrm{HxR}^{[40,42]}$.

\subsection{Effect of storage time on dielectric properties}

As the storage time increased, the composition of salmon muscle changed, which resulted in a variation in its dielectric properties. Figure 4 and Figure 5 showed the dielectric properties of refrigerated salmon during cold storage time at the measured frequency of 20-2500 MHz. It could be found from Figures 4 and 5 that within the measured frequency, $\varepsilon^{\prime}$ and $\varepsilon^{\prime \prime}$ had a similar trend that they both decreased with the increase of frequency, and increased with the storage time. Also, the increase at low-frequency range $(<300 \mathrm{MHz})$ was significantly higher than that at high-frequency range $(300-2500 \mathrm{MHz})$. With the increase of frequency, the molecule dipole rotation becomes a dominant mechanism in food materials, which leads to the decrease of $\varepsilon^{\prime}$ with the increase of frequency. In the radio frequency band $(<300 \mathrm{MHz})$, ion conduction is dominant, and as the frequency increased ( $>300 \mathrm{MHz})$, dielectric loss is mainly affected by dipole polarization. It was also found that along with the storage time, both the dielectric constant and loss factor of salmon flesh increased. This might be the combined effect of the protein degradation, lipids oxidation and microbial growth within the fish, since the accelerated metabolism and protein degradation of salmon 
meats produced an increase in metabolites and free ions, causing a higher ionic loss. Also, as the protein degraded, the water holding capacity of the muscle decreased, resulting in the loss of free water

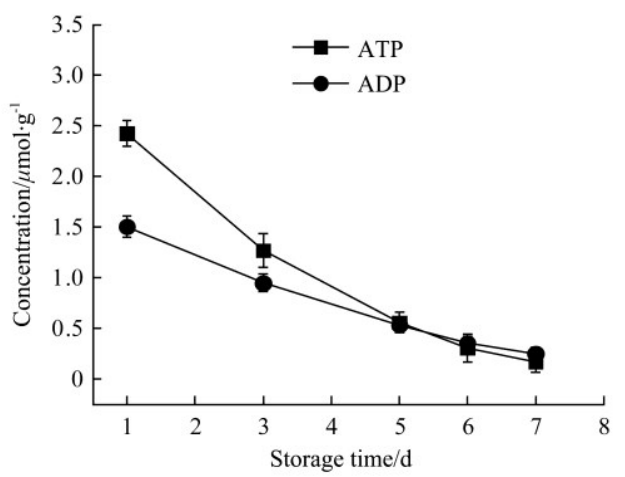

a.

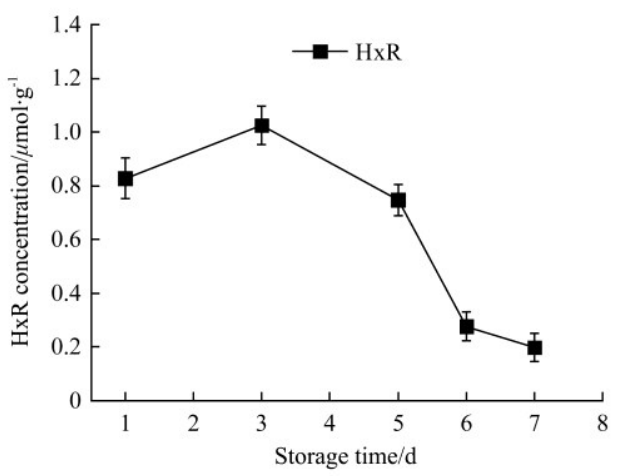

c. and further affecting the dielectric properties of salmon. These phenomena affect ionic conductivity and also the dipolar relaxation, as well dielectric properties ${ }^{[14]}$.

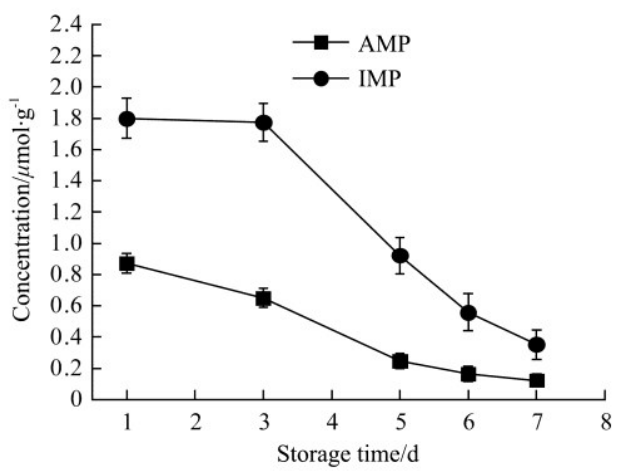

b.

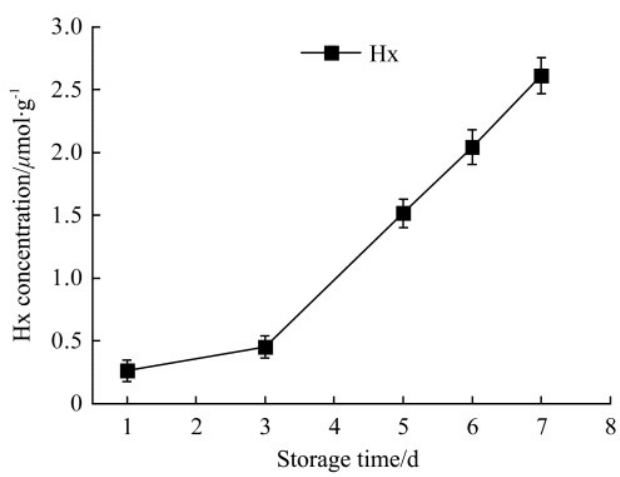

d.

Figure 3 Changes in concentration of ATP-related compounds of salmon fillets during storage at $4^{\circ} \mathrm{C}$

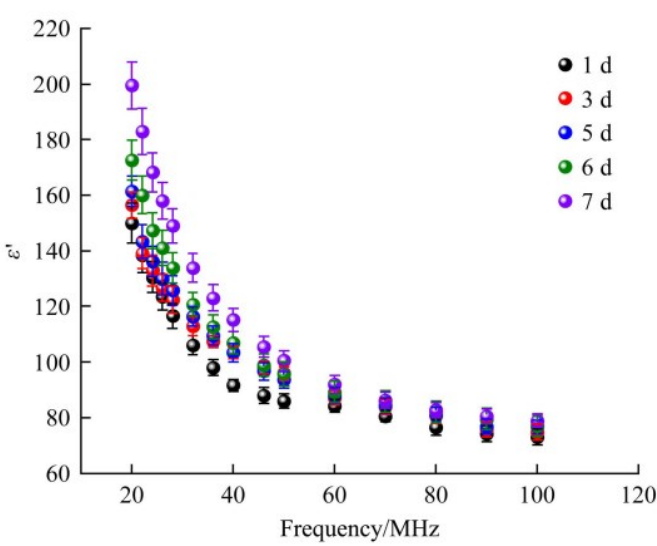

a. $\varepsilon^{\prime}$ measured at the frequency of 20-100 MHz

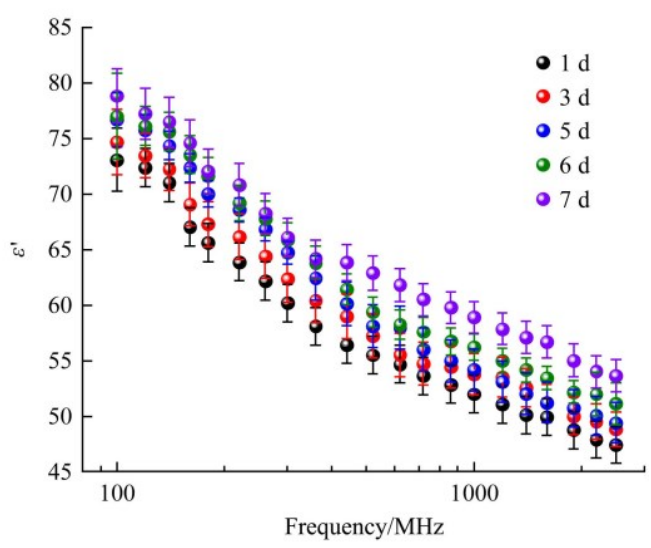

b. $\varepsilon^{\prime}$ measured at the frequency of 100-2 $500 \mathrm{MHz}$

Figure 4 Effect of the storage time on the dielectric constant $\left(\varepsilon^{\prime}\right)$ of salmon fillets stored at $4^{\circ} \mathrm{C}$ at the frequency of $20-2500 \mathrm{MHz}$.

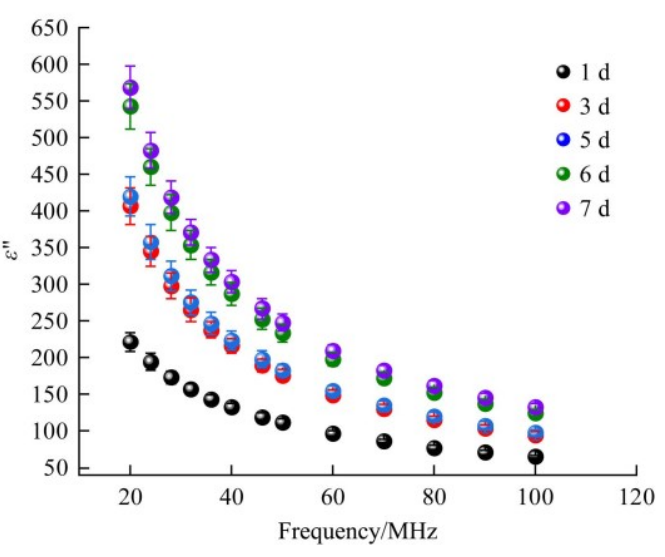

a. $\varepsilon^{\prime \prime}$ measured at the frequency of $20-100 \mathrm{MHz}$

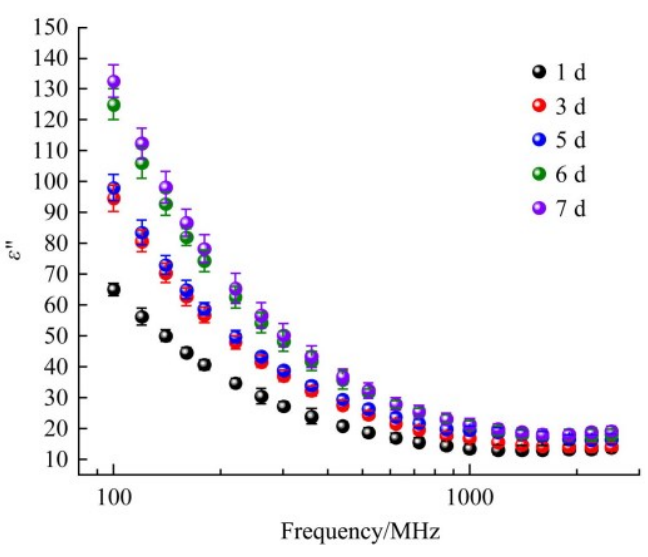

b. $\varepsilon^{\prime \prime}$ measured at the frequency of 100-2 $500 \mathrm{MHz}$

Figure 5 Effect of storage time on the electric loss $\left(\varepsilon^{\prime \prime}\right)$ of salmon stored at $4{ }^{\circ} \mathrm{C}$ at the frequency of $20-2500 \mathrm{MHz}$ 
Within the measured frequency range, the dielectric properties of salmon fillet at four frequencies $(27.12,40.68,915,2450 \mathrm{MHz})$ were selected and analyzed with the cold storage time (Figure 6). At 27.12 and $40.68 \mathrm{MHz}$, the $\varepsilon^{\prime}$ increased from $116.78 \pm 2.05$, $91.53 \pm 1.82$ to $149.72 \pm 2.43,115.90 \pm 2.21$, while the $\varepsilon "$ increased from $221.79 \pm 10.81$ and $133.03 \pm 3.45$ to $568.39 \pm 7.14$ and $303.53 \pm 2.30$, respectively. Under the same conditions, the $\varepsilon^{\prime}$ at 915 and $2450 \mathrm{MHz}$ increased from $52.57 \pm 0.66$ and $47.51 \pm 0.66$ to $60.36 \pm 1.45$ and $55.70 \pm 1.44$ while the dielectric loss $\varepsilon "$ increased from $14.29 \pm 1.06$ and $13.18 \pm 1.10$ to $22.40 \pm 1.52$ and $20.63 \pm 1.49$, respectively. The cell metabolism continued after the death of fish, but the cells cannot decompose and consume themselves during the storage, thus, the accumulation of products and free ions increased. Most of the metabolites are charged, resulting in more ion loss and dipole polarization, which is characterized by the increase of dielectric properties ${ }^{[11,14]}$. In addition, since the dielectric properties are related to the food composition ${ }^{[8,43]}$, the changes in the chemical composition of fish muscle and the destruction of cell structure will affect the dielectric properties to a certain extent during the storage of salmon.

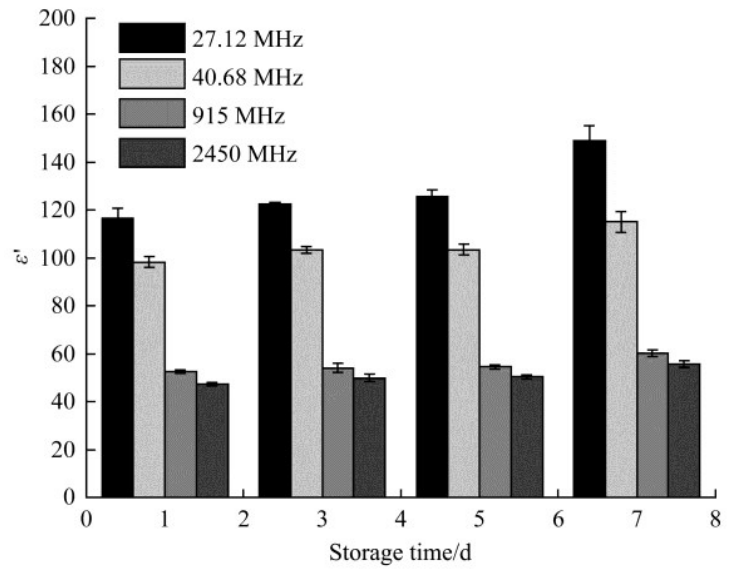

a.

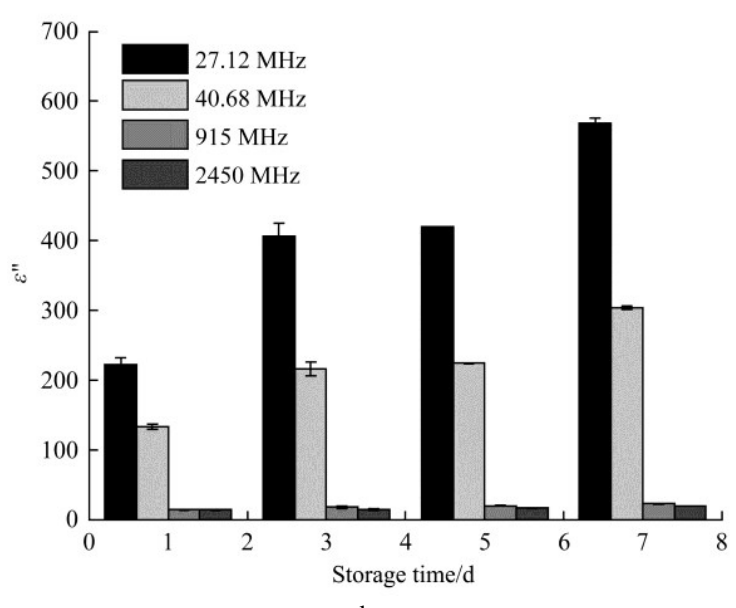

b.

Figure 6 Dielectric properties of salmon at the frequency of 27.12, 40.68, 915 and $2450 \mathrm{MHz}$ during different refrigerated storage

3.5 Correlation analysis between dielectric properties and physiochemical parameters

The dielectric properties and quality changes of salmon fillets both changed with storage time. Thus, a Pearson's correlation was established at six selected frequencies $(27.12,40.68,100,300$, 915 and $2450 \mathrm{MHz}$ ) to analyze the correlation. It could be seen from Table 1 that the correlations between $\varepsilon^{\prime \prime}$ and TVB-N, TBARS,
TVC, and K-value were mostly higher than that of $\varepsilon^{\prime}$, except for $\mathrm{pH}$. At six selected frequencies, there was a significant correlation $(p<0.05)$ between $\varepsilon^{\prime \prime}$ and quality indexes (except for $\mathrm{pH}$ ), especially between $\varepsilon "$ and TVB-N and TBARS which showed a very significant correlation $(p<0.01)$, except for the frequency of $2450 \mathrm{MHz}$. As a result, it was inferred that $\varepsilon$ " was more suitable to be used for predicting the quality changes of salmon fillets during storage at $4^{\circ} \mathrm{C}$.

Table 1 Pearson's correlations analysis and levels of significance for correlation between dielectric properties $\left(\varepsilon^{\prime}, \varepsilon^{\prime \prime}\right)$ and quality of salmon during refrigeration storage at the frequency of 27.12, 40.68, 100, 300, 915 and $2450 \mathrm{MHz}$.

\begin{tabular}{|c|c|c|c|c|c|}
\hline \multirow{2}{*}{$\begin{array}{l}\text { Dielectric } \\
\text { properties }\end{array}$} & TVB-N & TBARS & TVC & $\mathrm{K}$-value & $\mathrm{pH}$ \\
\hline & \multicolumn{5}{|c|}{ Pearson's $r$} \\
\hline$\varepsilon_{27.12}^{\prime}$ & $0.933^{*}$ & $0.929^{*}$ & $0.935^{*}$ & $0.969^{* *}$ & 0.861 \\
\hline$\varepsilon_{40.68}^{\prime}$ & $0.949^{*}$ & $0.946^{*}$ & $0.914^{*}$ & $0.916^{*}$ & 0.650 \\
\hline$\varepsilon_{100}^{\prime}$ & $0.892 *$ & $0.890 *$ & $0.889 *$ & $0.931 *$ & 0.842 \\
\hline$\varepsilon_{300}^{\prime}$ & $0.981 * *$ & $0.982 * *$ & $0.976^{* *}$ & $0.973 * *$ & 0.845 \\
\hline$\varepsilon_{915}^{\prime}$ & 0.874 & 0.874 & 0.822 & 0.768 & 0.396 \\
\hline$\varepsilon_{2450}^{\prime}$ & 0.872 & 0.874 & 0.811 & 0.754 & 0.387 \\
\hline$\varepsilon^{\prime \prime} 27.12$ & $0.973^{* *}$ & $0.975^{* *}$ & $0.938^{*}$ & $0.910^{*}$ & 0.669 \\
\hline$\varepsilon^{\prime \prime} 40.68$ & $0.975^{* *}$ & $0.977 * *$ & $0.941^{*}$ & $0.917 *$ & 0.687 \\
\hline$\varepsilon_{100}^{\prime \prime}$ & $0.977^{* *}$ & $0.979 * *$ & $0.948^{*}$ & $0.929^{*}$ & 0.722 \\
\hline$\varepsilon_{300}^{\prime \prime}$ & $0.979 * *$ & $0.981^{* *}$ & $0.952 *$ & $0.930^{*}$ & 0.728 \\
\hline$\varepsilon " 915$ & $0.981 * *$ & $0.984 * *$ & $0.963 * *$ & $0.923^{*}$ & 0.716 \\
\hline$\varepsilon_{2450}^{\prime \prime}$ & $0.924^{*}$ & $0.927 *$ & $0.949^{*}$ & $0.910^{*}$ & 0.822 \\
\hline
\end{tabular}

Note: Levels of significance for correlation are defined as $* p<0.05, * * p<0.01$, respectively.

\subsection{PLS prediction model}

The PLS- $\varepsilon^{\prime}$ and PLS- $\varepsilon "$ regression models were established for the $\varepsilon^{\prime}$ and $\varepsilon^{\prime \prime}$ of salmon fillets during cold storage to predict the TVB-N, TBARS and TVC. Table 2 listed the results of modeling with PLS. Also, the predicted values against experimental values plots for TVB-N, TBARS and TVC of salmon samples were shown in Figure 7. From Table 2, it could be found that the highest $R_{\text {pred }}^{2}$ and the lowest RMSEP were obtained respectively when using $\varepsilon^{\prime}$ and $\varepsilon^{\prime \prime}$ to predict the TVB-N and TBARS, which were 0.940, 0.944 and 0.041, 0.039, respectively, thus showing a more accurate prediction of TVB-N due to the highest $R_{\text {pred }}^{2}$. To illustrate the fitness of the PLS model, Figure 7 presented good correlations between the three predicted values of quality parameters with measured values. The correlation coefficients for the models PLS- $\varepsilon^{\prime}$ and PLS- $\varepsilon$ " to predict TVB-N, TBARS and TVC were 0.937, 0.910, 0.917 and $0.942,0.917$ and 0.933 , respectively.

Table 2 Predicted determination coefficient $\left(R_{\text {pred }}^{2}\right)$ and root mean square deviation (RMSEP) obtained from PLS model based on dielectric properties

\begin{tabular}{cllc}
\hline Independent variable & \multicolumn{1}{c}{ Dependent variable } & $R_{\text {pred }}^{2}$ & RMSEP \\
\hline$\varepsilon^{\prime}$ & TVB-N $/ \mathrm{mg} \cdot 100 \mathrm{~g}^{-1}$ & 0.940 & 0.897 \\
$\varepsilon^{\prime}$ & TBARS $/ \mathrm{mg} \mathrm{MDA} \cdot \mathrm{kg}^{-1}$ & 0.913 & 0.041 \\
$\varepsilon^{\prime}$ & $\mathrm{TVC} / \log \left(\mathrm{CFU} \cdot \mathrm{g}^{-1}\right)$ & 0.920 & 0.292 \\
$\varepsilon^{\prime \prime}$ & $\mathrm{TVB}-\mathrm{N} / \mathrm{mg} \cdot 100 \mathrm{~g}^{-1}$ & 0.944 & 0.859 \\
$\varepsilon^{\prime \prime}$ & $\mathrm{TBARS} / \mathrm{mg} \mathrm{MDA} \cdot \mathrm{kg}^{-1}$ & 0.920 & 0.039 \\
$\varepsilon^{\prime \prime}$ & $\mathrm{TVC} / \log \left(\mathrm{CFU} \cdot \mathrm{g}^{-1}\right)$ & 0.935 & 0.262 \\
\hline
\end{tabular}




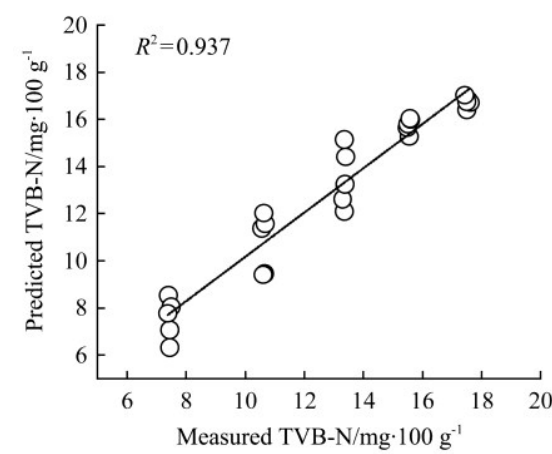

a.

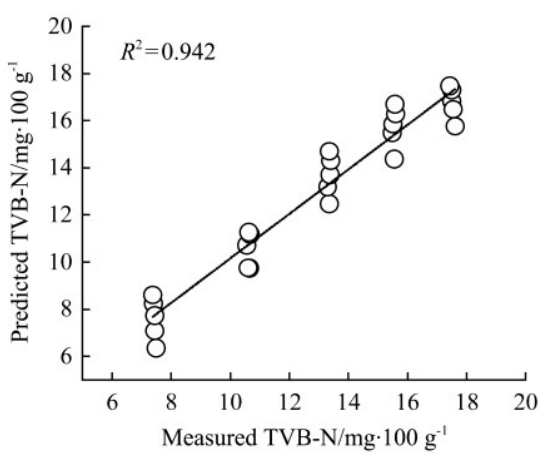

d.
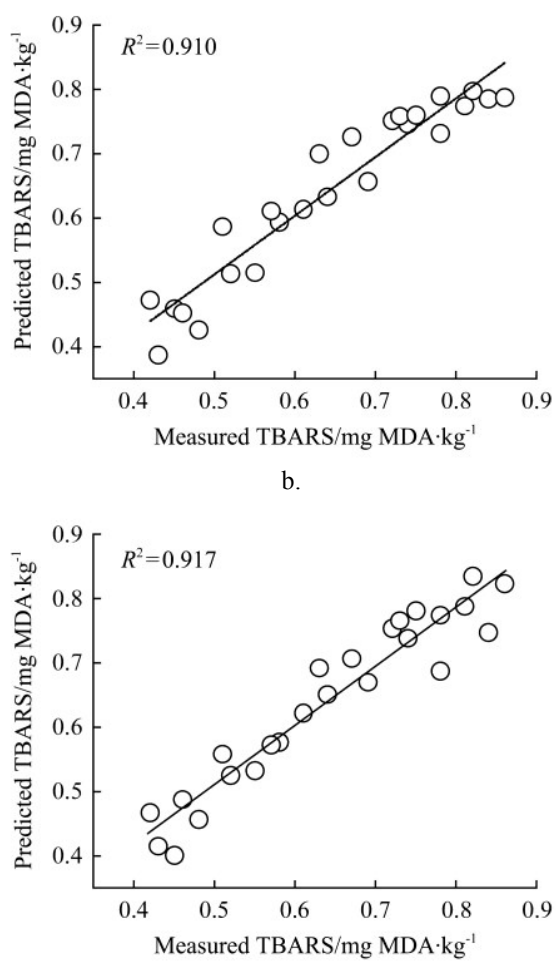

e.
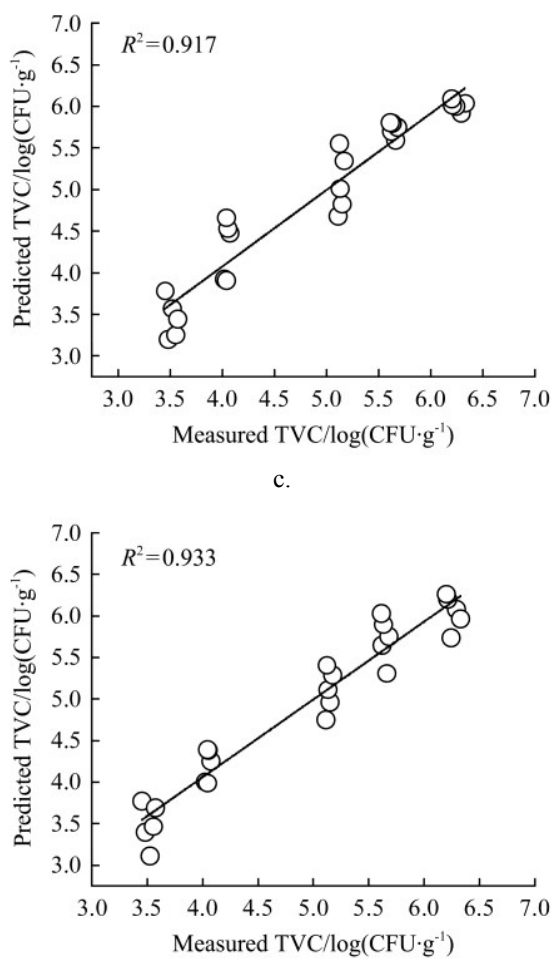

f.

Figure 7 PLS prediction model of quality variables (TVB-N, TBARS and TVC) based on the dielectric properties ( $\varepsilon^{\prime}$ and $\left.\varepsilon^{\prime \prime}\right)$ of salmon during storage ((a), (b), (c) are quality predictions based on $\varepsilon^{\prime} ;$ (d), (e), (f) are quality predictions based on $\left.\varepsilon^{\prime \prime}\right)$

\section{Conclusions}

In this study, a reliable method using dielectric properties $\left(\varepsilon^{\prime}\right.$ and $\left.\varepsilon^{\prime \prime}\right)$ of salmon at $4{ }^{\circ} \mathrm{C}$ to predict the quality parameters (TVB-N, TBARS and TVC) was developed based on the PLS method. The highest $R_{\text {pred }}^{2}$ and lowest RMSEP were found in TVB-N and TBARS. The $R_{\text {pred }}^{2}$ for TVB-N were 0.940 (PLS- $\left.\varepsilon^{\prime}\right)$ and 0.944 (PLS- $\left.\varepsilon^{\prime \prime}\right)$, and RMSEP for TBARS were 0.041 (PLS- $\varepsilon^{\prime}$ ) and 0.039 (PLS- $\varepsilon ")$, respectively. The $R^{2}$ of TVB-N, TBARS and TVC of salmon obtained from the predicted versus reference plots were all above 0.910. Thus, it was concluded that the proposed methodology was proved to be accurate for evaluating the quality and freshness of salmon fillets during cold storage at $4^{\circ} \mathrm{C}$. Future studies could focus on temperature variation influence on the dielectric properties and the quality attributes of salmon.

\section{Acknowledgements}

The authors acknowledge the National Natural Science Foundation of China (Grant No. 31801613) for financial support to this research, and Professor Peng Zhang from Xidian University for his assistance in the data processing.

\section{[References]}

[1] Vinagre J, Rodríguez A, Larraín M A, Aubourg S P. Chemical composition and quality loss during technological treatment in coho salmon (Oncorhynchus kisutch). Food Research International, 2011; 44(1): 1-13.

[2] Li X, Chen Y, Cai L, Xu Y, Yi S, Zhu W, et al. Freshness assessment of turbot (Scophthalmus maximus) by Quality Index Method (QIM), biochemical, and proteomic methods. LWT-Food Science and Technology, 2017; 78: 172-180.

[3] Liu D S, Liang L, Xia W S, Regenstein J M, Zhou P. Biochemical and physical changes of grass carp (Ctenopharyngodon idella) fillets stored at -3 and $0^{\circ} \mathrm{C}$. Food Chemistry, 2013; 140(1-2): 105-114.

[4] Li Y, Zhuang S, Liu Y, Zhang L, Liu J, Shu R, et al. Effect of grape seed extract on quality and microbiota community of container-cultured snakehead (Channa argus) fillets during chilled storage. Food Microbiology, 2020; 91: 103492. doi: 10.1016/j.fm.2020.103492.

[5] $\mathrm{Li} \mathrm{T}, \mathrm{Li} \mathrm{J}, \mathrm{Hu}$ W. Changes in microbiological, physicochemical and muscle proteins of post mortem large yellow croaker (Pseudosciaena crocea). Food Control, 2013; 34(2): 514-520.

[6] Liang Y, Xie Y, Li D, Luo Y, Hong H. Dynamics of water mobility, salt diffusion and hardness changes in bighead carp fillets during low-salting. LWT-Food Science and Technology, 2021; 135. doi: 10.1016/ j.lwt.2020.110033.

[7] Fidalgo L G, Lemos Á T, Delgadillo I, Saraiva J. Microbial and physicochemical evolution during hyperbaric storage at room temperature of fresh Atlantic salmon (Salmo salar). Innovative Food Science \& Emerging Technologies, 2018; 45: 264-272.

[8] Al-holy M, Wang Y, Tang J, Rasco B. Dielectric properties of salmon (Oncorhynchus keta) and sturgeon (Acipenser transmontanus) caviar at radio frequency (RF) and microwave (MW) pasteurization frequencies. Journal of Food Engineering, 2005; 70(4): 564-570.

[9] Guo W, Zhu X, Nelson S O, Yue R, Liu H, Liu Y. Maturity effects on dielectric properties of apples from 10 to $4500 \mathrm{MHz}$. LWT - Food Science and Technology, 2011; 44(1): 224-230.

[10] Guo W, Fang L, Liu D, Wang Z. Determination of soluble solids content and firmness of pears during ripening by using dielectric spectroscopy. Computers and Electronics in Agriculture, 2015; 117: 226-233.

[11] Guo W C, Zhu X H, Liu H, Yue R, Wang S J. Effects of milk concentration and freshness on microwave dielectric properties. Journal of Food Engineering, 2010; 99(3): 344-350.

[12] Castro-Giráldez M, Toldrá F, Fito P. Low frequency dielectric measurements to assess post-mortem ageing of pork meat. LWT - Food Science and Technology, 2011; 44(6): 1465-1472.

[13] Damez J-L, Clerjon S, Abouelkaram S, Lepetit J. Beef meat electrical impedance spectroscopy and anisotropy sensing for non-invasive early assessment of meat ageing. Journal of Food Engineering, 2008; 85(1): $116-122$.

[14] Castro-Giráldez M, Aristoy M C, Toldrá F, Fito P. Microwave dielectric spectroscopy for the determination of pork meat quality. Food Research International, 2010; 43(10): 2369-2377.

[15] Chevalier D, Ossart F, Ghommidh C. Development of a non-destructive salt and moisture measurement method in salmon (Salmo salar) fillets using impedance technology. Food Control, 2006; 17(5): 342-347.

[16] Fernández-Segovia I, Fuentes A, Aliño M, Masot R, Alcañiz M, Barat J M. Detection of frozen-thawed salmon (Salmo salar) by a rapid low-cost 
method. Journal of Food Engineering, 2012; 113(2): 210-216.

[17] Ragni L, Al-Shami A, Mikhaylenko G, Tang J. Dielectric characterization of hen eggs during storage. Journal of Food Engineering, 2007; 82(4): 450-459.

[18] Kuson P, Terdwongworakul A. Minimally-destructive evaluation of durian maturity based on electrical impedance measurement. Journal of Food Engineering, 2013; 116(1): 50-56.

[19] Rossi G B, Lozano V A. Simultaneous determination of quality parameters in yerba mate (Ilex paraguariensis) samples by application of near-infrared (NIR) spectroscopy and partial least squares (PLS). LWT-Food Science and Technology, 2020; 126: 109290. doi:10.1016/j.lwt.2020.109290.

[20] Shrestha L, Crichton S O J, Kulig B, Kiesel B, Hensel O, Sturm B. Comparative analysis of methods and model prediction performance evaluation for continuous online non-invasive quality assessment during drying of apples from two cultivars. Thermal Science and Engineering Progress, 2020; 18: 100461. doi:10.1016/j.tsep.2019.100461.

[21] GB 2733-2015. National Health and Family Planning Commission. National standard for food safety of fresh and frozen animal aquatic products. Beijing: China Standard Press, 2015. (in Chinese)

[22] Zhu Y, Li F, Tang J, Wang T, Jiao Y. Effects of radio frequency, air and water tempering, and different end - point tempering temperatures on pork quality. Journal of Food Process Engineering, 2019; 42(4): e13026. doi: $10.1111 /$ jfpe. 13026

[23] GB 4789.2-2016. State Food and Drug Administration, National Health and Family Planning Commission. Determination of total number of bacterial colonies in food microbiological inspection of national standard for food safety. Beijing: China Standard Press, 2016. (in Chinese)

[24] Zhuang S, Li Y, Hong H, Liu Y, Shu R, Luo Y. Effects of ethyl lauroyl arginate hydrochloride on microbiota, quality and biochemical changes of container-cultured largemouth bass (Micropterus salmonides) fillets during storage at $4^{\circ} \mathrm{C}$. Food Chemistry, 2020; 324: 126886. doi: 10.1016/ j.foodchem.2020.126886.

[25] Zhao X, Zhou Y, Zhao L, Chen L, He Y, Yang H. Vacuum impregnation of fish gelatin combined with grape seed extract inhibits protein oxidation and degradation of chilled tilapia fillets. Food Chemistry, 2019; 294: 316-325.

[26] Li D, Zhang L, Song S, Wang Z, Kong C, Luo Y. The role of microorganisms in the degradation of adenosine triphosphate (ATP) in chill-stored common carp (Cyprinus carpio) fillets. Food Chemistry, 2017; 224: 347-352.

[27] Huang Z, Liu X, Jia S, Luo Y. Antimicrobial effects of cinnamon bark oil on microbial composition and quality of grass carp (Ctenopharyngodon idellus) fillets during chilled storage. Food Control, 2017; 82: 316-324.

[28] Li S, Li F, Tang J, Koral T, Jiao Y. Influence of composition, temperature, and frequency on dielectric properties of selected saltwater and freshwater fish. International Journal of Food Properties, 2019; 22(1): 1920-1934.

[29] Lau S K, Subbiah J. An automatic system for measuring dielectric properties of foods: Albumen, yolk, and shell of fresh eggs. Journal of Food Engineering, 2018; 223: 79-90.

[30] Fernandes D D D S, Romeo F, Krepper G, Nezio M S D, Pistonesi M,
Cemturión M E, et al. Quantification and identification of adulteration in the fat content of chicken hamburgers using digital images and chemometric tools. LWT-Food Science and Technology, 2019; 100: 20-27.

[31] Bedin F C B, Faust M V, Guarneri G A, Assmann T S, Lafay C B B, Soares L F, et al. NIR associated to PLS and SVM for fast and non-destructive determination of $\mathrm{C}, \mathrm{N}, \mathrm{P}$, and $\mathrm{K}$ contents in poultry litter. Spectrochimica Acta Part A: Molecular Biomolecular Spectroscopy, 2021; 245: 118834. doi:10.1016/j.saa.2020.118834.

[32] Ramezani Z, Zarei M, Raminnejad N. Comparing the effectiveness of chitosan and nanochitosan coatings on the quality of refrigerated silver carp fillets. Food Control, 2015; 51: 43-48.

[33] Yuan G, Lyu H, Tang W, Zhang X, Sun H. Effect of chitosan coating combined with pomegranate peel extract on the quality of Pacific white shrimp during iced storage. Food Control, 2016; 59: 818-823.

[34] Song Y, Liu L, Shen H, You J, Luo Y. Effect of sodium alginate-based edible coating containing different anti-oxidants on quality and shelf life of refrigerated bream (Megalobrama amblycephala). Food Control, 2011; 22(3-4): 608-615.

[35] Yu D, Renenstein J M, Zang J, Xia W, Xu Y, Jiang Q, et al. Inhibitory effects of chitosan-based coatings on endogenous enzyme activities, proteolytic degradation and texture softening of grass carp (Ctenopharyngodon idellus) fillets stored at 4 degrees C. Food Chemistry, 2018; 262: 1-6.

[36] Yu D, Regenstein J M, Zang J, Xia W, Xu Y, Jiang Q, et al. Inhibition of microbial spoilage of grass carp (Ctenopharyngodon idellus) fillets with a chitosan-based coating during refrigerated storage. International Journal of Food Microbiology, 2018;285: 61-68.

[37] Qin N, Li D, Hong H, Zhang Y, Zhu B, Luo Y. Effects of different stunning methods on the flesh quality of grass carp (Ctenopharyngodon idellus) fillets stored at 4 degrees C. Food Chemistry, 2016; 201: 131-138.

[38] Shiba T, Shiraki N, Furushita M, Maeda T. Free amino acid and ATP-related compounds in sterile tiger puffer fish (Takifugu rubripes) fillets stored at 4C. Journal of Food Processing and Preservation, 2014; 38(3): 791-797.

[39] Liu Q, Wu J E, Lim Z Y, Aggarwal A, Yang H, Wang S. Evaluation of the metabolic response of Escherichia coli to electrolysed water by $1 \mathrm{H} \mathrm{NMR}$ spectroscopy. LWT - Food Science and Technology, 2017; 79: 428-436.

[40] Zhao X, Wu J, Chen L, Yang H. Effect of vacuum impregnated fish gelatin and grape seed extract on metabolite profiles of tilapia (Oreochromis niloticus) fillets during storage. Food Chemistry, 2019; 293 418-428.

[41] Hernandez-Cazares A S, Aristoy M C, Toldra F. Nucleotides and their degradation products during processing of dry-cured ham, measured by HPLC and an enzyme sensor. Meat Science, 2011; 87(2): 125-129.

[42] Yu D, Xu Y, Regenstein J M, Xia W, Yang F, Jiang Q, et al. The effects of edible chitosan-based coatings on flavor quality of raw grass carp (Ctenopharyngodon idellus) fillets during refrigerated storage. Food Chemistry, 2018; 242: 412-420.

[43] Guo W, Trabelsi S, Nelson S O, Jones D R. Storage effects on dielectric properties of eggs from 10 to $1800 \mathrm{MHz}$. Journal of Food Science, 2007; 72(5): 335-340. 